\title{
Comparative analysis of Optical Microscopy, Scanning Electron Microscopy, and Micro-Computed Tomography on measurements
}

Frederick Khalil Karam, DDS, MSc ${ }^{1}$, Karla Zancope, DDS, MSc, PhD 1 , Thiago de Almeida Prado Naves Carneiro, DDS, MSc, PhD¹, Murilo Navarro de Oliviera, DDS candidate, Caio César Dias Resende, DDS, MSc ${ }^{1}$, Flávio Domingues das Neves, DDS, MSc, $\mathrm{PhD}^{1}$

1 Department of Occlusion, Fixed Prosthodontics and Dental Materials, School of Dentistry, Federal University of Uberlândia, Uberlândia, MG, Brazil.
Corresponding author: Prof. Dr. Flávio Domingues das Neves

Av. Pará, 1720, Bloco 4L, Anexo A sala 4LA-42, Campus Umuarama, CEP: 38405-320, Uberlândia, Minas Gerais, Brazil E-mail: neves@triang. com br Phone: +55-34-3218-2222 Fax: $+55-34-3218-2626$

Received: June 02, 2017

Accepted: September 20, 2017

\section{(i)}

Abstract: Microscopic measurements are widely used in scientific research and the correct equipment to perform these evaluations could be critical to determine study results. Regarding microscopic measurements, three of the most used methods are: Optical Microscopy (OM), Scanning Electron Microscopy (SEM), and Micro-computed Tomography (MCT). It is important to select the best method for assessing diverse parameters, considering operational characteristics of the method, the equipment efficiency, and the machinery cost. Aim: Therefore, the main objective of this study was to define which is the most useful measurement method for assessing magnitudes below $0.4 \mathrm{~mm}$. Methods: Ten dental implants, with known dimensions as defined by the manufacturer were randomly distributed. Two blinded observers assessed the distance between the second and the third screw vortex of the implants using three suggested methods. The true distance was defined to be $0.5 \mathrm{~mm}$. Results: The assessed distances were: $0.597 \pm 0.007 \mathrm{~mm}$ for OM, $0.578 \pm 0.017 \mathrm{~mm}$ for SEM, and $0.613 \pm 0.006 \mathrm{~mm}$ for MCT. The assessed distances were significantly different when the methods were compared $(P>0.01)$. All measurements were into the $\mathrm{CAD}$ tolerances. Conclusion: It was possible to conclude that linear measurements between 595 and $605 \mu \mathrm{m}$ could be performed by any of the described technologies.

Keywords: measurements, dental implants, optical microscope, micro-CT, electron microscope. 


\section{Introduction}

The application of the correct measurement method for microscopic analysis on scientific research is crucial to obtain reliable values, which will not cause distortions on investigation results ${ }^{1,2}$. The choose of the correct method will diverge according to the study objectives and the material to be evaluated ${ }^{3}$. Some other variables should be considered to final decision, like operator dexterity with the equipment, apparatus disposition and machinery operation cost; however these aspects could not interfere on results trustworthiness ${ }^{4,5}$. Before adopting any technology to measure samples, the operator needs to consider the main objective of the study and what part of the sample must be analysed ${ }^{6,7}$. The election of an inadequate measurement technique may lead to an unnecessary use of method, with consequently depreciation of the equipment and waste of time. Lack of necessary data could make an inconclusive study ${ }^{8}$.

Among diversified researches, Dentistry, and specifically Implant Dentistry requires micrometric examinations to define security measurements. Implant manufacturing, requires meticulous and preciseregulations ${ }^{9,10}$. Measurements and surface analysis at lower scales of the dental implants and their fitting components during their fabrication should be severally reliable to ensure a satisfactory piece seating and consequently, the rehabilitation biomechanical success ${ }^{11,12}$. Therefore, the correct methodology application during the implant manufacturing by the producer are directly connected to the therapy prosperity ${ }^{13}$.

In dispersion through the most used approaches to realize micrometric analysis are: Optical Microscope (OM), a two-dimensional evaluation method that uses a series of glass lenses to create a limited magnification, is widely used for surface quantitative mensuration ${ }^{22,14}$. Scanning Electron Microscope (SEM), an electronic microscope that could provide surface images with high resolution and magnification ${ }^{15,16}$ and Micro-Computed Tomography (micro-CT), a non-destructive method that allows high-resolution tridimensional analysis, without damaging the sample ${ }^{17}$.

Therefore, the aim of this study was to evaluate the three method's precision, comparing to O.M., S.E.M. and Micro-CT on dental implants mensuration, checking for possible images distortions, according to manufacturer tolerance limits. The null hypothesis was there was no statistic difference between the three evaluated methodologies, presenting all values into a confidence interval.

\section{Material and methods}

Initially, two evaluators were randomly recruited to perform the measurements of all tested methodologies. These evaluators did not know what they would evaluate and were trainee to perform ruler measurements. Ten dental implants (Titamax $3.75 \mathrm{~mm} \times 13 \mathrm{~mm}$; Neodent, Curitiba, Brazil) were selected for this study, and distance between vertex to vertex from the second to the third screw was chosen to be measured in all methods described below. An implant, to be manufactured, is design first in CAD, and then sent to the milling machine. The CAD used to produce these implants was requested, in order to establish what is the real distance from vertex 
to vertex of these implants. Therefore, the CAD of the implant itself was used as a control. The samples were positioned on a device to standardize the position of the implant to each method.

\section{Optical Microscope (OM)}

The samples were fixed in an Optical Microscope (Mitutoyo TM-500, Tokyo, Japan) to perform the implant mensuration. This is a monocular microscope with two digital micrometers and0.001 resolution. The equipment has objective lenses with $2 x$ magnification and ocular lenses with 20x magnification, resulting in a 40x enlargement. The pixel resolution obtained is $5 \mathrm{MP}$ (mega pixel). The microscope has a holder over all the samples that allow the positioned sample to move over the $\mathrm{X}$ and $\mathrm{Y}$-axes, during the mensuration (Fig. 1).

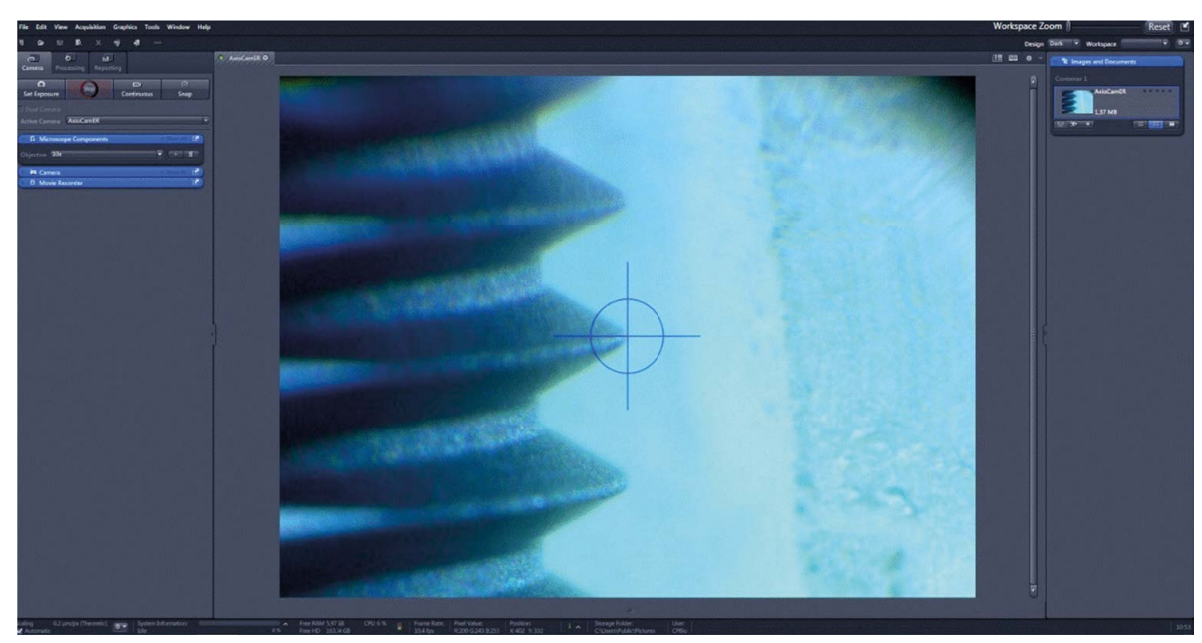

Figure 1. Optical Microscope obtained image, and vortex marking to the distance calculation.

\section{Scanning Electron Microscope (SEM)}

The SEM used in this study (Hitachi, Chiyoda-ku, Tokyo, Japan) operates in different pressure conditions, controlled by a computer using the Windows operational system (LOQUIF software, Leo User Interface, Carl Zeiss, Oberkochen, Germany). Magnification of 150x was applied. The pixel resolution obtained is $5 \mathrm{MP}$. The measurements were realized directly on the equipment software (Fig. 2).

\section{Micro-computed tomography (micro-CT)}

The implants were scanned using a computed microtomography (Skyscan 1272, Konith, Belgium). The used parameters were: $100 \mathrm{kV}$ voltage source, 100A chain source, $2452 \times 1640$ resolution, 20 pixels, 18.0 Cu filter, 0.2 degrees rotation step, 20 aleatory movements and images average of 2, rotation step (deg) 1000, averag- 


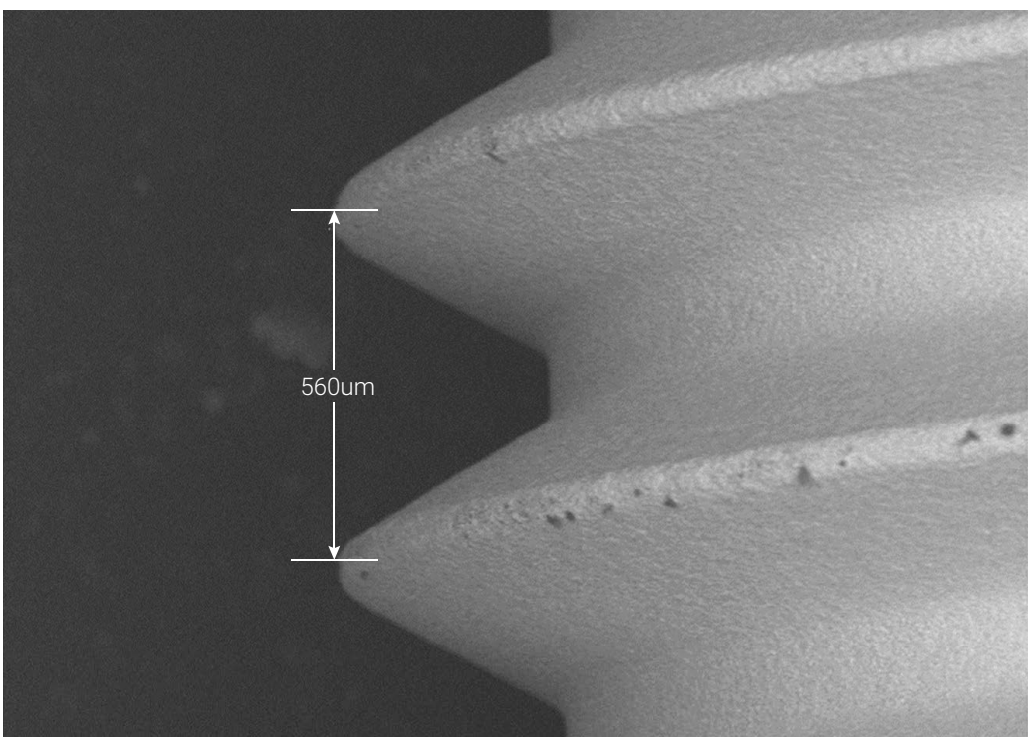

Figure 2. SEM surface image and software vortex to vortex measurement.

ing frames of 2, random movement (pix) of 20, Pixel Size 18.0 MP and the standard scan in central camera position. After these parameters definition, the samples were removed of the tomography and a flat-field was requested to generate smaller artifacts in the final image. The scanning time was set to 26 minutes, for this kind of evaluation (Fig. 3)

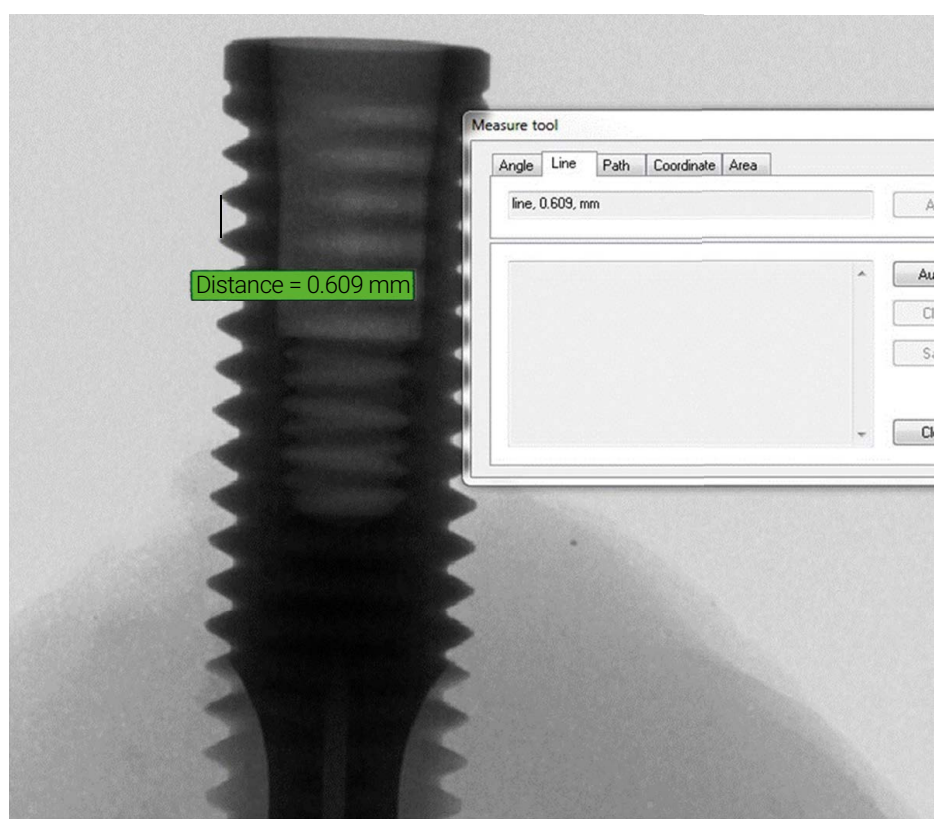

Figure 3. Micro-CT constructed image and measure tool utilization. 
Two blinded evaluators performed all measurements, and the mean values of each sample were considered for statistical evaluation (Sigmaplot 12.0, Systat Software Inc, USA). The data were initially submitted to the variance homogeneity and normality tests $(a=0.05)$. To compare all groups, the Anova One Way statistical method was applied before the Tukey Test. To compare each group with the CAD (control group), the t-test was applied.

A qualitative evaluation was also applied, to define if the values were into a confidence interval, defined by implant' manufacturer. The control group was considered by the CAD image of the tested implant, provided by manufacturer.

\section{Results}

The mean values of all methodologies, between both evaluators, are shown in Table 1. There were statistical differences between all tested methodologies. However, according to a qualitative evaluation, all methodologies presented acceptable values, when comparing to the CAD (control group), according to Table 2.

Table 1. Dental implants vertex to vertex average and standard deviation evaluation. Letters between parentheses demonstrate statistical differences.

\begin{tabular}{lcccc}
\hline Group & Samples & Average & Standard Deviation & P Value \\
\hline M.C.T. & 10 & $0.613(\mathrm{~A})$ & 0.00624 & $<0.001$ \\
\hline O.M. & 10 & $0.597(\mathrm{~B})$ & 0.00664 & $<0.001$ \\
\hline S.E.M. & 10 & $0.578(\mathrm{C})$ & 0.00168 & $<0.001$ \\
\hline
\end{tabular}

Table 2. Evaluations average. The provided company CAD (control) was inserted on the first line. The second, third and fourth line were the groups values.

\begin{tabular}{lcc}
\hline Group & Minimal Value & Maximal Value \\
\hline Control & 0.550 & 0.650 \\
\hline O.P.T.(A) & 0.588 & 0.607 \\
\hline M.E.V.(A) & 0.560 & 0.611 \\
\hline M.C.T.(A) & 0.604 & 0.617 \\
\hline
\end{tabular}

\section{Discussion}

The null hypothesis that, there was no statistic difference between all evaluated methodologies presenting all values into a confidence interval, was reject. The results demonstrated in Table 1 prove that there is statics difference between the three tested groups. However, all values were into a fabrication tolerance, defined by manufacturer. This qualitative evaluation define the values into the CAD's tolerance, produced by the milling machine, but do not affect the implant's quality. The values of the CAD were between $595 \mu \mathrm{m}$ and $605 \mu \mathrm{m}$. Any value into this interval was considered acceptable. 
Regardless of the methodology, the operator factor could directly influence any study that uses measurements. Two blind evaluators were used to determine the distance between two determined points. They were instructed only to measure the distance between the vortices of the second and third threads of dental implants. The evaluators were not influenced in any way about the location of the selected point. The operator factor is directly related to the results of any measurement and therefore was discussed. That's why the authors used ten implants on each methodology: to decrease operators' bias (mean $\pm S D$ ). It is uncommon, in literature, studies that indicate the specific criteria used for evaluation in a measurement methodology; it is only reported which methodology was used for evaluation. Several studies ${ }^{18-22}$ evaluated marginal fit using different methodologies for measurements. But to decrease operators' bias, the studies used more then one operator to perform measurements.

According to a previous study ${ }^{23}$, the $\mathrm{OM}$ is the best methodology to superficially measure the spaces. The OM demonstrates lower spatial resolutions, making it difficult the using for analysis of ultrafine deformations and strain measurements ${ }^{24}$. It is the cheaper technology compared to the other methods, and is easy handling equipment, which does not, requires a special training to use it. For these reason this methodology could be indicated technology to external analysis with values between $595 \mu \mathrm{m}$ and $605 \mu \mathrm{m}$. However, it is important to emphases that all methodologies allow the visualization in two dimensions, and could be an important limitation. Some studies ${ }^{18,20}$ that performed internal measurements, these methodologies could not be used.

The SEM is an alternative methodology that produces high-resolution images down to the nanometer scale and provides reliable measurement data using image analysis methods, such as digital Image correlation ${ }^{16}$. In meantime, alerts that SEM images are usually contaminated with distortions and drift aberrations that could disturb the accuracy of imaging and measurement ${ }^{24}$. To analyze organic materials, such as the needing of a specialized apparatus and the risk of damage to the samples caused by the vacuum pressure in tem $\mathrm{SEM}^{3}$, could interfere on studies with human tissues measurements, for example. In the present study, the evaluators related a complexity to use this equipment, once the samples preparing and readout were more complicated compared with the other technologies. The price of the equipment would not justify the using for linear analysis above $605 \mu \mathrm{m}$, due all methodologies are statistical equal. However, for measurements below this value, some studies presents advantages to this equipment $7,8,12,16,25$

According to the literature, Micro-CT is a faster method that limits the manual error that occurs using the $\mathrm{OM}$, which is an optically based measurement, being susceptible to human failures ${ }^{26}$. Beside that, the Micro-CT technology can extract 3D information, different of the 2D information obtained in optical measurements. The quality of Micro-CT images, and the advantages of being a non-damage technique proposing this technology utilization to quantify mistakes on techniques with less image qual$i^{2} y^{27}$. But is a methodology used only on in vitro studies, despites the high radiation and the time spent on scanning, reconstruction and measurement; making this technology impracticable during the clinical routine ${ }^{28}$. Instead the related works affirms ${ }^{26}$, our study shows that Micro-CT method takes more scanning time than the other methodologies, moreover, is an expensive equipment, which limits the utilization for 
large scale measurements. The convenience observed using microtomography is the possibility to realize internal analysis without damaging the samples ${ }^{29}$. In this work there was no advantage with this equipment utilization, once this technology requires specifically preparation and is an expensive machinery compared with the OM.

The statistical differences found at the present study makes it impossible to compare the three methodologies, although all measurements obtained are in the manufacturing tolerance, it could not be considered as accurate. Considering the results of this study, any methodology can be used to measure values larger than $0.5 \mathrm{~mm}$. So, authors should choose the methodology passed in two different parameters: first, the most familiar methodology to researcher and second, less cost and time to be done. In addition, the SEM image quality and the non-destruction of samples in Micro-CT are determinant in the results. Future studies could evaluate the influence of methodologies in smaller measurements with values below $0.5 \mathrm{~mm}$.

In conclusion, all measurements were into the CAD tolerances. It was possible to conclude that linear measurements between 595 and $605 \mu \mathrm{m}$ could be performed by any of the described technologies.

\section{Acknowledgements}

The authors would like to thank the researchers Rubens Spin Neto, Marcel Santana Prudente, Neodent, Fapemig, CAPES and Research Center for Biomechanics, Biomaterials and Cell Biology (CPBio - UFU)

\section{References}

1. Chatburn RL. Evaluation of instrument error and method agreement. AANA J. 1996 Jun;64(3):261-8.

2. Ludbrook J. Statistical techniques for comparing measurers and methods of measurement: a critical review. Clin Exp Pharmacol Physiol. 2002 Jul;29(7):527-36.

3. Landis JB, Ventura KL, Soltis DE, Soltis PS, Oppenheimer DG. Optical Sectioning and 3D reconstructions as an alternative to scanning electron microscopy for analysis of cell shape. Appl Plant Sci. 2015 Apr 3;3(4). pii: apps.1400112. doi: 10.3732/apps. 1400112.

4. Karras DJ. Statistical methodology: II. Reliability and validity assessment in study design, Part B. Acad Emerg Med. 1997 Feb;4(2):144-7.

5. Watson PF, Petrie A. Method agreement analysis: a review of correct methodology. Theriogenology. 2010 Jun;73(9):1167-79. doi: 10.1016/j.theriogenology.2010.01.003.

6. White SA, van den Broek NR. Methods for assessing reliability and validity for a measurement tool: a case study and critique using the WHO haemoglobin colour scale. Stat Med. 2004 May 30;23(10):1603-19.

7. Edwards R. Two-dimensional convolute integers for analytical instrumentation. Anal Chem. 1982;54:1519-24

8. Shaw DE, Jones HS, Moseley MJ. Analysis of method-comparison data. Ophthalmic Physiol Opt. 1994 Jan;14(1):92-6.

9. Gaviria L, Salcido JP, Guda T, Ong JL. Current trends in dental implants. J Korean Assoc Oral Maxillofac Surg. 2014 Apr;40(2):50-60. doi: 10.5125/jkaoms.2014.40.2.50. 
10. Tomsia AP, Launey ME, Lee JS, Mankani MH, Wegst UGK, Saiz E. Nanotechnology approaches for better dental implants. Int J Oral Maxillofac Implants. 2011;26:25-49.

11. Brånemark P-I, Zarb GA, Albrektsson T. Tissue-integrated prostheses. Chicago: Quintessence; 1985. $352 \mathrm{p}$.

12. Faria KO, Silveira-Junior CD, Silva-Neto JP, Mattos MGC, Silva MR, Neves FD. Comparison of methods to evaluate implant-abutment interface. Braz J Oral Sci. 2013;12(1):37-40.

13. Coelho PG, Jimbo R. Osseointegration of metallic devices: current trends based on implant hardware design Arch Biochem Biophys. 2014 Nov 1;561:99-108. doi: 10.1016/j.abb.2014.06.033.

14. Hecker DM, Eckert SE. Cyclic loading of implant-supported prostheses: changes in component fit over time. J Prosthet Dent. 2003 Apr;89(4):346-51.

15. Hultin M, Komiyama A, Klinge B. Supportive therapy and the longevity of dental implants: a systematic review of the literature. Clin Oral Implants Res. 2007 Jun;18 Suppl 3:50-62.

16. Neves FD, Elias GA, Silva-Neto JP, Dantas LCM, Mota AS, Neto AJF. Comparison of implant-abutment interface misfits after casting and soldering procedures. J Oral Implantol. 2014 Apr;40(2):129-35. doi: 10.1563/AAID-JOI-D-11-00070

17. Finelle G, Papadimitriou DE, Souza AB, Katebi N, Galucci GO, Araújo MG. Peri-implant soft tissue and marginal bone adaptation on implant with non-matching healing abutments: micro-CT analysis. Clin Oral Implants Res. 2015 Apr;26(4):e42-6. doi: 10.1111/clr.12328.

18. Gomes RS, Souza CMC, Bergamo ETP, Bordin D, Del Bel Cury AA. Misfit and fracture load of implant-supported monolithic crowns in zirconia-reinforced lithium silicate. J Appl Oral Sci. 2017 May-Jun;25(3):282-289. doi: 10.1590/1678-7757-2016-0233.

19. Neves FD, Prado CJ, Prudente MS, Carneiro TA, Zancope K, Davi LR, et al. Microcomputed tomography marginal fit evaluation of computer-aided design/computer-aided manufacturing crowns with different methods of virtual model acquisition. Gen Dent. 2015 May-Jun;63(3):39-42

20. Prudente MS, Davi LR, Nabbout KO, Prado CJ, Pereira LM, Zancopé K, et al. Influence of scanner, powder application, and adjustments on CAD-CAM crown misfit. J Prosthet Dent. 2017 Jul 7. pii: S0022-3913(17)30280-9. doi: 10.1016/j.prosdent.2017.03.024.

21. M. Kurz, T. Attin, A. Mehl Influence of material surface on the scanning error of a powder-free 3D measuring system. Clin Oral Investig. 2015 Nov;19(8):2035-43. doi: 10.1007/s00784-015-1440-5

22. L. Jahangiri, D. Estafan A method of verifying and improving internal fit of all-ceramic restorations. J Prosthet Dent. 2006 Jan;95(1):82-3.

23. Katsoulis J, Merickse-Stern R, Rotkina L, Zbären C, Enkling N, Blatz MB. Precision of fit of implant supported screw-retained 10-unit computer-aided-designed and computer-aided-manufactured frameworks made from zirconium dioxide and titanium: an in vitro study. Clin Oral Implants Res. 2014 Feb;25(2):165-74. doi: 10.1111/clr.12039.

24. Jin P, Li X. Correction of image drift and distortion in a scanning electron microscopy. J Microsc. 2015 Dec;260(3):268-80. doi: 10.1111/jmi.12293.

25. Groten M, Axmann D, Pröbster L, Weber H. Determination of the minimum number of marginal gap measurements required for practical in-vitro testing. J Prosthet Dent. 2000 Jan;83(1):40-9.

26. Kline TL, Zamir M, Ritman EL. Accuracy of microvascular measurements obtained from micro-CT images. Ann Biomed Eng. 2010 Sep;38(9):2851-64. doi: 10.1007/s10439-010-0058-7.

27. Mangione F, Meleo D, Talocco M, Pecci R, Pacifici L, Bedini R. Comparative evaluation of the accuracy of linear measurements between cone beam computed tomography and 3D microtomography. Ann Ist Super Sanita. 2013;49(3):261-5.DOI: 10.4415/ANN_13_03_05. 
28. Özkan G, Kanli A, Başeren NM, Arslan U, Tatar I. Validation of micro-computed tomography for occlusal caries detection: an in vitro study. Braz Oral Res. 2015;29(1):S1806-83242015000100309. doi: 10.1590/1807-3107BOR-2015.vol29.0132

29. Grande NM, Plotino G, Gambarini G, Testarelli L, D’Ambrosio F, Pecci R, et al. Present and future in the use of micro-CT scanner 3D analysis for the study of dental and root canal morphology. Ann Ist Super Sanita. 2012;48(1):26-34.DOI: 10.4415/ANN_12_01_05. 